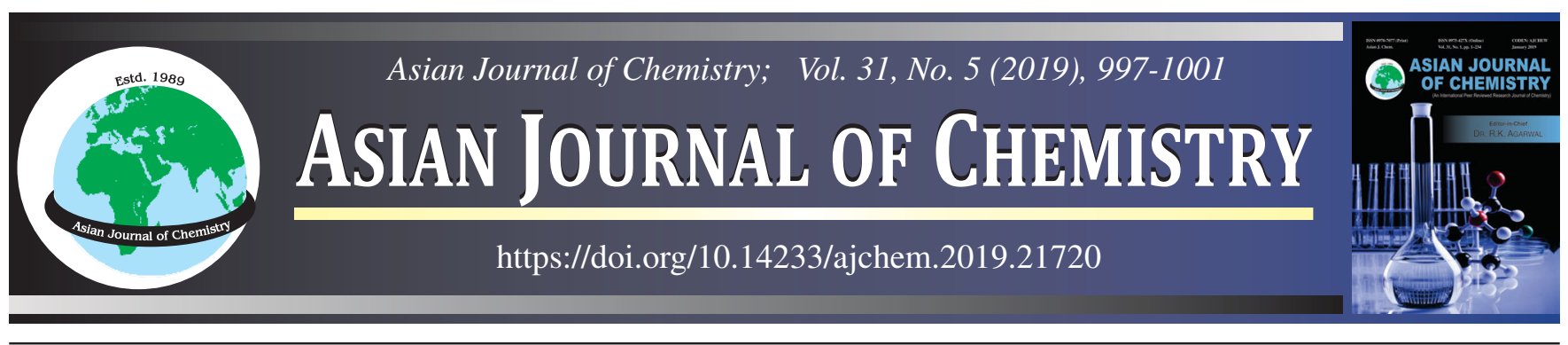

\title{
Synthesis and Characterization of Certain Photoactive Liquid Crystalline Poly(ester amides) from 2,5-Pyridine Dicarboxylic Acid
}

\author{
V. CHITRA* and D. Roopsingh
}

PG and Research Department of Chemistry, Presidency College, University of Madras, Chennai-600 005, India

*Corresponding author: Fax: +91 44 28510732, E-mail: chit.neha07@ gmail.com

Received: 24 September 2018;

Accepted: 29 November 2018;

Published online: 28 March 2019;

AJC-19319

\begin{abstract}
A new series of four photo-crosslinkable thermotropic liquid crystalline poly(ester amides) were synthesized by direct polycondensation of 2,5-pyridine dicarboxylic acid with two different varying diols and diamines. Two diamines employed in the synthesis were 4,4'diaminodiphenyl methane and 1,4-diaminobenzene. The arylidene diols 2,5-bis(4-hydroxy-3-methoxybenzylidene)cyclopentanone and 2,6-bis(4-hydroxy-3-methoxybenzylidene)cyclohexanone were also used. The synthesized poly(ester amides) were characterized by qualitative solubility test, FT-IR, ${ }^{1} \mathrm{H}$ and ${ }^{13} \mathrm{C}$ NMR spectra. The monomeric moieties were found to be well incorporated in the polymer back bone. The molecular weight of the polymer was assessed by gel permeation chromatography (GPC). The thermal phase transition behavior and liquid crystallinity of the poly(ester amides) were investigated by differential thermogravimetry (DTG) and hot stage optical polarized microscopy (HOPM), respectively. Interestingly, these poly(ester amides) in dimethylacetamide were found to possess photo-crosslinking characteristics when irradiated by UV light. These polymeric materials may find utility value in optical information storage devices.
\end{abstract}

Keywords: Arylidene diols, Poly(ester amides), Liquid crystals, Photocrosslinking.

\section{INTRODUCTION}

Poly(ester amides) are considered to be important class of polymeric materials in recent years as they possess polyester and polyamide building blocks in a single molecule. Poly(ester amides) form strong intermolecular hydrogen bonding which can enhance the limited mechanical and thermal properties of the materials [1]. The polymers incorporated arylidene diol moiety find uses in many fields such as surgical devices, thermoplastic materials, scaffolds in tissue engineering, cell encapsulation and injectable drug delivery [2-5]. Sudha [6] has synthesized certain thermotropic liquid crystalline aromatic-aliphatic poly(ester-amide)s from amido diol.

Abdolmaleki et al. [7] reported the synthesis of novel nanostructured aromatic optically active poly(ester amides) derived from biodegradable polymers containing S-tyrosine amino acids. Song et al. [8] have been investigated the synthesis of electroactive and biodegradable multiblock copolymers based on poly(ester-amide) and aniline oligomers. Pinilla et al. [9] evidenced that high molecular weight poly(ester amides) can be prepared from carbohydrates bearing methoxyl groups along the polymer backbone. Synthesis of novel biodegradable poly(ester amides) having ether linkages in the backbone chain by ring-opening copolymerization was studied by $\mathrm{Li}$ et al. [10]. The difference in the thermal properties of segmented poly(ester amides) has been evaluated. Generally, thermal properties were dependent on the microstructure of polymers. The structure-property relationship is essential for designing polymeric materials [11]. The photo-crosslinkable thermotropic liquid crystalline polymers containing bis(benzylidene)cycloalkanone groups have also been extensively studied [12]. Shibaev [13] found applications in the field of developing optical information storage devices and non-linear optical materials.

Murali and Samui [14] reported an excellent review concerning bisbenzylidene cycloalkanone as a polymer building block and its significance in various fields. Ankushrao et al. [15] recently reported the synthesis of novel aromatic poly(ester amides) containing cyclopentylidene moiety in the polymer backbone to improve the solubility and processability of polymers.

Synthesis of poly(ester amides) from wide range of monomers can lead to linear or hyper branched molecular arrangements [16]. Many synthetic methods to produce poly(ester

This is an open access journal, and articles are distributed under the terms of the Creative Commons Attribution-NonCommercial-ShareAlike 4.0 (CC BY-NC-SA 4.0) International License which allows readers to freely read, download, copy, distribute, print, search, or link to the full texts of its articles and to use them for any other lawful non-commercial purpose as long as the original source is duly acknowledged. 
amides) have been proposed. But one of the easiest and most studied methods is direct polycondensation. In this study, we report on the synthesis and characterization of photocrosslinkable liquid crystalline poly(ester amides) obtained from a common diacid namely 2,5-pyridine dicarboxylic acid with two different diamines and two different bis(benzylidene)cycloalkanone diols using diphenylchlorophosphate (DPCP) as polycondensation agent in pyridine medium. From the data, a correlation between optical properties and polymeric structure is discussed.

\section{EXPERIMENTAL}

Aldrich samples of 2,5-pyridine dicarboxylic acid, 4,4'diaminodiphenyl methane, 1,4-diaminobenzene, diphenylchlorophosphate (99\%) and anhydrous lithium chloride (99\%) were used as received. Cyclopentanone and cyclohexanone were purchased from SRL and freshly distilled in the laboratory. Merck sample of pyridine was refluxed over $\mathrm{KOH}$ pellets and distilled $\left(115^{\circ} \mathrm{C}\right)$. It was preserved in amber coloured bottles over $\mathrm{KOH}$ pellets. Merck samples of other solvents such as tetrahydrofuran and methanol were distilled at their boiling point before use. Spectral grade DMSO- $d_{6}$ (Aldrich) containing TMS as internal standard was used as such for recording NMR spectrum.

Preparation of arylidene diol: The synthesis of arylidene diol, namely, 2,5-bis(4-hydroxy-3-methoxy benzylidene)cyclopentanone was carried out according to the procedure as reported by Mayavathi et al. [17]. Briefly, a mixture of $18.5 \mathrm{~g}$ (0.15 mol) 4-hydroxy-3-methoxybenzaldehyde and $6.31 \mathrm{~g}(0.075$ mol) cyclopentanone was dissolved in $75 \mathrm{~mL}$ of dry methanol and maintained in ice cold condition. To this mixture, catalytic amount of conc. sulphuric acid was added slowly dropwise and kept for $24 \mathrm{~h}$. The product was filtered, washed several times with distilled water and dried. The crude monomer was recrystallized twice from methanol to yield yellowish green crystals. m.p. $212{ }^{\circ} \mathrm{C}$. Yield: $85 \%$ FT-IR (KBr, $\left.v_{\max }, \mathrm{cm}^{-1}\right)$ : $2923\left(\mathrm{CH}_{2}\right), 1674$ (cyclopentanone $\left.\mathrm{C}=\mathrm{O}\right), 3338(\mathrm{OH})$ and 1593 $(\mathrm{C}=\mathrm{C})$.

The other arylidenediol, 2,6-bis(4-hydroxy-3-methoxybenzylidene)cyclohexanone was also synthesized as above mentioned procedure.

Synthesis of poly(ester amides): The polymers (Table-1) were prepared by direct polycondensation as according to the following procedure.

In a three necked $250 \mathrm{~mL}$ round bottomed flask equipped with a condenser, thermometer and mechanical strirrer (400 $\mathrm{rpm} / \mathrm{min})$ in an oil bath, $0.835 \mathrm{~g}(5 \mathrm{mmol})$ of 2,5-pyridine dicarboxylic acid in $10 \mathrm{~mL}$ pyridine and $2.694 \mathrm{~mL}(13 \mathrm{mmol})$ diphenylchlorophosphate (DPCP) were added. After stirring for $20 \mathrm{~min}, 0.4250 \mathrm{~g}(10 \mathrm{mmol})$ of $\mathrm{LiCl}$ in $10 \mathrm{~mL}$ pyridine

\begin{tabular}{lcccl}
\multicolumn{5}{c}{ TABLE-1 } \\
\multicolumn{5}{c}{$\begin{array}{c}\text { POLYMER CODE, MONOMERS USED, YIELD, } \\
\text { INHERENT VISCOSITY AND COLOUR }\end{array}$} \\
\hline $\begin{array}{c}\text { Polymer } \\
\text { code }\end{array}$ & Monomers & $\begin{array}{c}\text { Yield } \\
(\%)\end{array}$ & $\begin{array}{c}\text { Inherent } \\
\text { viscosity }(\mathrm{dL} / \mathrm{g})\end{array}$ & Colour \\
\hline PAPM & PD + AP + DM & 84 & 1.16 & Grey \\
PAPB & PD + AP + DB & 65 & 1.20 & Black \\
PAHM & PD + AH + DM & 78 & 1.18 & Black \\
PAHB & PD + AH + DB & 80 & 1.23 & Brown \\
\hline
\end{tabular}

PD: 2,5-pyridine dicarboxylic acid; AP: 2,5-bis(4-hydroxy-3-methoxy benzylidene)cyclopentanone; AH: 2,6-bis(4-hydroxy-3-methoxybenzylidene)cyclohexanone; DM: 4,4'-diamino diphenyl methane; DB: 1,4-diamino benzene.

was added and the stirring was continued at room temperature for $30 \mathrm{~min}$. The reaction mixture was slowly heated and maintained at $120^{\circ} \mathrm{C}$ for $20 \mathrm{~min}$. To this mixture, $0.88 \mathrm{~g}(2.5 \mathrm{mmol})$ of 2,5-bis(4-hydroxy-3-methoxybenzylidene)cyclopentanone in $5 \mathrm{~mL}$ pyridine and $0.495 \mathrm{~g}(2.5 \mathrm{mmol})$ of $4,4^{\prime}$-diaminodiphenyl methane in $5 \mathrm{~mL}$ pyridine were added dropwise simultaneously at $120^{\circ} \mathrm{C}$ and the whole solution was further stirred under the same condition for $3 \mathrm{~h}$. The solution was cooled to room temperature and poured into $500 \mathrm{~mL}$ water/methanol $(1: 1 \mathrm{v} / \mathrm{v})$ mixture. The product was filtered, washed with hot methanol and dried in sunlight. Similarly, all the other poly(ester amides) were prepared in the same method having same monomer feed ratio.

\section{RESULTS AND DISCUSSION}

Solubility of poly(ester amides): The solubility of all the synthesized poly(ester amides) are listed in Table-2. The poly(ester amides) derived from aromatic dicarboxylic acid were found to be easily soluble in highly polar solvents such as dimethylformamide (DMF), dimethylacetamide (DMAc) dimethyl sulphoxide (DMSO) and tetrahydrofuran (THF) partially soluble in acetone, chloroform and sparingly soluble in common organic solvents like methanol, benzene and hexane.

FTIR analysis: The representative FT-IR spectrum of poly(ester amide) (PAPM) is shown in Fig.1. The vibration at $1740 \mathrm{~cm}^{-1}$ is attributed to $\mathrm{C}=\mathrm{O}$ ester linkage which confirms the completion of polymerization. The characteristic carbonyl stretching frequency of cyclopentanone ring appeared at 1673 $\mathrm{cm}^{-1}$. The aromatic $\mathrm{C}=\mathrm{C}$ is shown at $1520 \mathrm{~cm}^{-1}$. The absorption due to $\mathrm{NH}$ bond of amide linkage is observed at $3338 \mathrm{~cm}^{-1}$. In addition, absorption at $1265 \mathrm{~cm}^{-1}$ was observed. This vibration is attributed to C-O-C of ester group and other characteristic absorptions appeared in the IR spectra indicate that the monomers are well incorporated into the polymer backbone of poly(ester amides). Similar FT-IR spectra with characteristic absorptions were also obtained for the other three poly(ester amides).

NMR analysis: The chemical repeat units in poly(ester amides) were identified by ${ }^{1} \mathrm{H}$ and ${ }^{13} \mathrm{C}$ NMR spectra. The typical

TABLE-2

SOLUBILITY OF THE POLY(ESTERAMIDES)

\begin{tabular}{cccccccccc}
\hline Polymer & Hexane & Benzene & $\mathrm{CHCl}_{3}$ & $\mathrm{THF}$ & Acetone & $\mathrm{CH}_{3} \mathrm{OH}$ & DMF & DMAc & DMSO \\
\hline PAPM & - & - & \pm & + & \pm & - & + & + & + \\
PAPB & - & - & \pm & + & \pm & - & + & + & + \\
PAHM & - & - & \pm & + & \pm & - & + & + & + \\
PAHB & - & - & \pm & + & \pm & - & + & + & + \\
\hline
\end{tabular}

$+=$ Highly soluble; $\pm=$ Partially soluble; $-=$ Sparingly soluble 


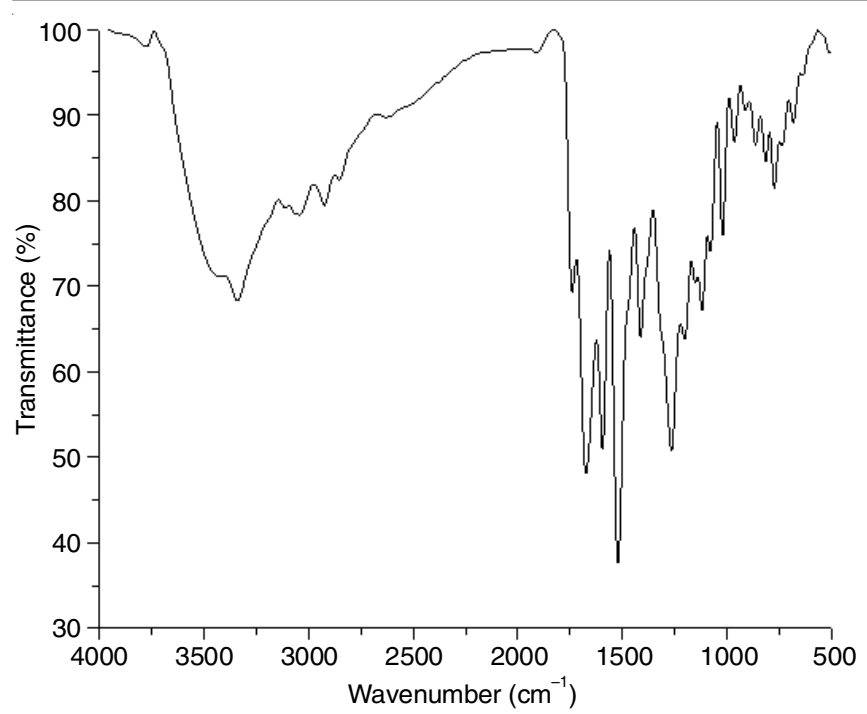

Fig. 1. FT-IR spectrum of PAPM

${ }^{1} \mathrm{HNMR}$ spectra of poly(ester amide) (PAPB) recorded in DMSO$d_{6}$ are shown in Fig. 2. The peak assigned to secondary amide group can be observed at $10.8 \delta$. The aromatic protons of benzylidine groups appeared in the range of 7.0-7.9 $\delta$. The aromatic protons of dicarboxylic acid appeared in the range of 8.2-8.3 $\delta$. The peaks at 6.8-6.9 $\delta$ are due to vinyllic proton associated with cyclopentyl ring. The peak corresponds to methylenic protons of cyclopentanone in arylidene keto moiety appeared in $2.5 \delta$. This data indicated that all the monomers are present in the polymer chain. The complete assignment of the signals confirms that two dicarboxylic acid moieties, one arylidene diol moiety and one diamine moiety are linked in the polymer backbone.

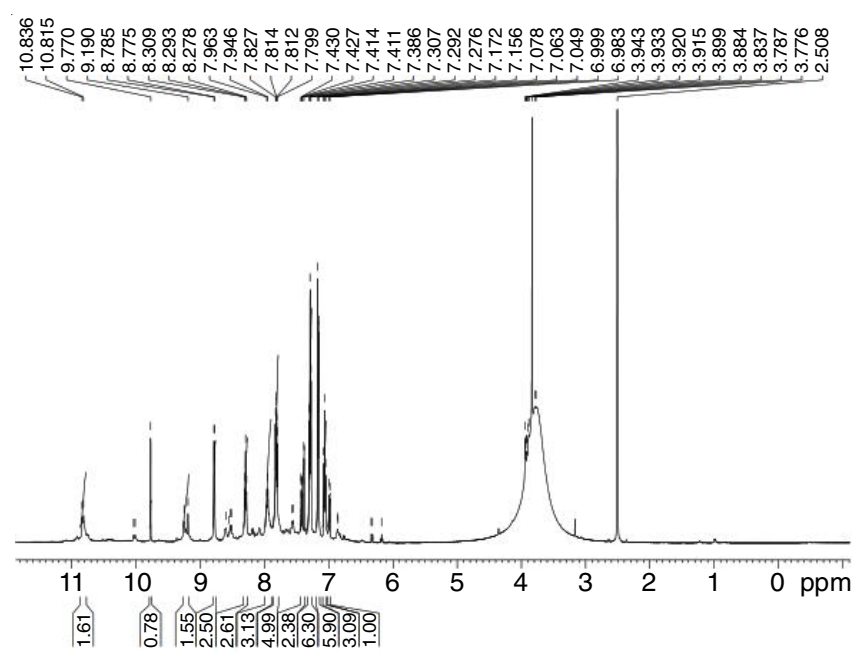

Fig. 2. ${ }^{1} \mathrm{H}$ NMR spectrum of PAPB

Another typical ${ }^{13} \mathrm{C}$ NMR spectra of poly(ester amide) (PAPB) is shown in Fig. 3. The carbonyl carbon of $\alpha, \beta$ - unsaturated ketone moiety appeared at $191 \mathrm{ppm}$. The aromatic carbons are indicated by the presence of signals in the range of 111$129 \mathrm{ppm}$. The signals from 142-153 ppm represent the olefinic carbon atoms of arylidene moiety. The carbons of amide carbonyl group indicated by the signal at $166 \mathrm{ppm}$. The signal at $56 \mathrm{ppm}$ assigned to methoxy carbon of bis(3-methoxybenzylidene) group. The methylenic carbon of cyclopentanone appeared in the range of 39-40 ppm.

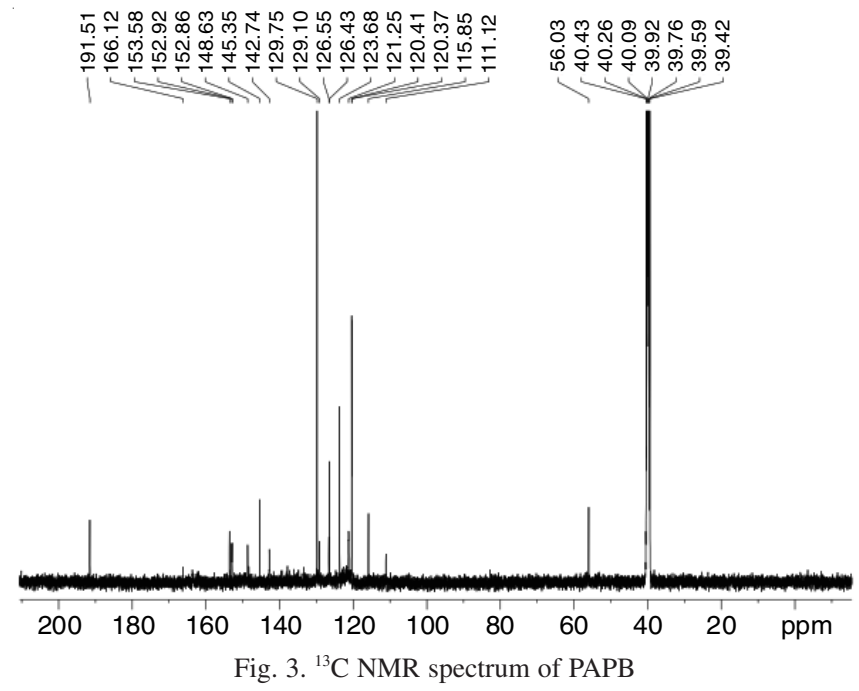

Thermal analysis: Thermogravimetry (TG) coupled with differential thermogravimetry (DTG) is a good thermoanalytical technique useful for identifying phase transitions of poly(ester amides). DTG thermograms were recorded in nitrogen atmosphere at a heating rate of $10{ }^{\circ} \mathrm{C} / \mathrm{min}$ from RT- $600{ }^{\circ} \mathrm{C}$ for poly(ester amide) (PAPM) in order to detect the phase transitions (Fig. 4). The thermal transition can be studied from the DTG thermograms. From Fig. 4, it can be observed that the glass transition of the sample starts the first inflection at $53.1^{\circ} \mathrm{C}$ and melting from $241.5^{\circ} \mathrm{C}$. The final clearance occurs at $491.9^{\circ} \mathrm{C}$. These transitions indicate that poly(ester amides) is liquid crystalline with characteristics mesophase range. Similar thermograms were obtained for all the poly(ester amides) and their thermal transition temperatures are tabulated in Table-3.

TABLE-3

THERMAL TRANSITION OF POLY(ESTER AMIDES)

\begin{tabular}{cccc}
\hline Polymer & $\mathrm{T}_{\mathrm{g}}\left({ }^{\circ} \mathrm{C}\right)$ & $\mathrm{T}_{\mathrm{m}}\left({ }^{\circ} \mathrm{C}\right)$ & $\mathrm{T}_{\mathrm{el}}\left({ }^{\circ} \mathrm{C}\right)$ \\
\hline PAPM & 53.1 & 241.5 & 491.9 \\
PAPB & 85.1 & 209.6 & 281.2 \\
PAHM & - & 263.9 & 453.8 \\
PAHB & 73.5 & 255.9 & 443.9 \\
\hline
\end{tabular}

Hot stage optical polarizing microscopy: Hot stage optical polarizing microscopy (HOPM) provides an efficient tool for determining the liquid crystalline properties of poly(ester amides). The synthesized poly(ester amides) were studied by HOPM and found to be liquid crystalline in nature. It is interesting to note that all the synthesized poly(ester amides) showed Schlieren texture in nematic mesophase in the temperature range 260$400{ }^{\circ} \mathrm{C}$ (Fig. 5). Arylidene diols containing cyclopentatone moiety are found to form mesophase at a lower temperature than those containing cyclohexanone moiety. This may be due to steric effect of cyclohexanone ring size being greater than that of cyclopentanone ring size.

Photocrosslinking studies: The synthesized poly(ester amides) contain arylidene diol moiety, which functions as photoactive chromophores will undergo photocrosslinking by UV irradiation. The UV visible spectra of poly(ester amides) were recorded in dimethylacetamide solution $\left(0.01 \mathrm{gd} \mathrm{L}^{-1}\right)$ successively after UV irradiation from a $160 \mathrm{~W}$ medium pressure mercury 


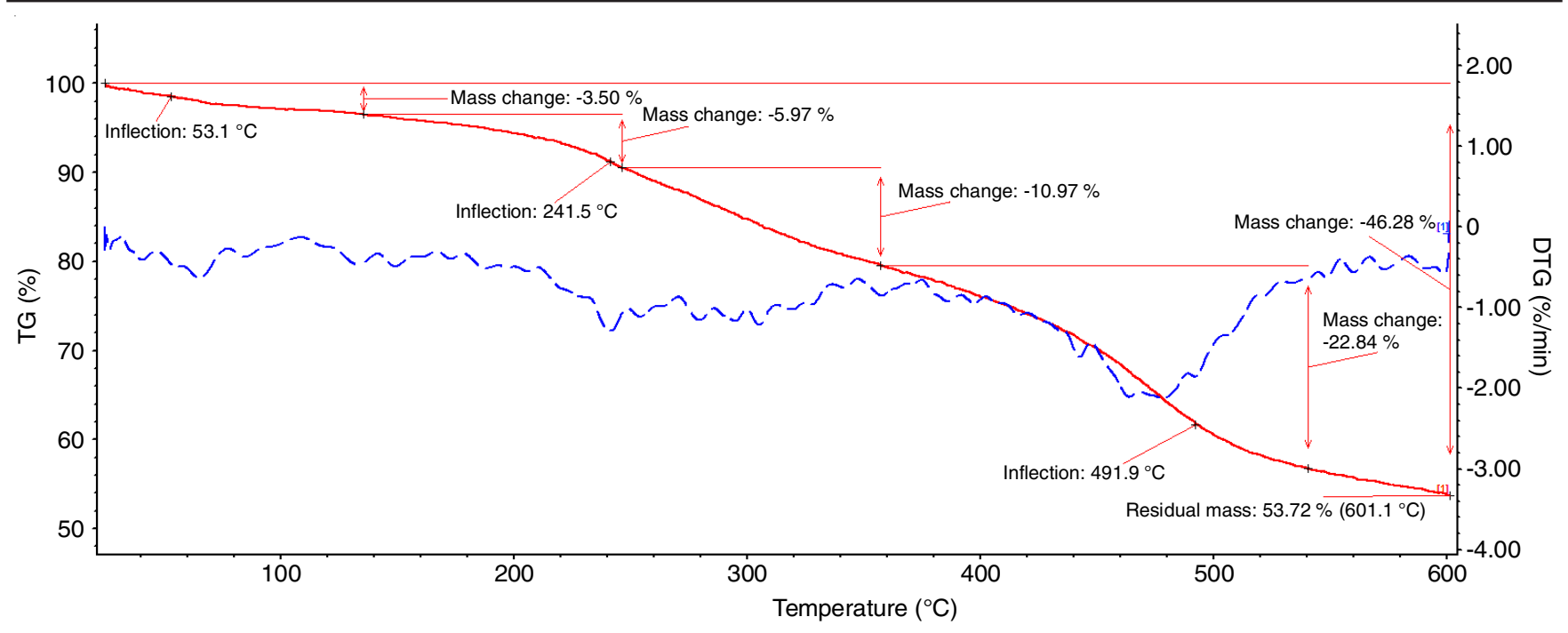

Fig. 4. DTG thermogram of PAPM
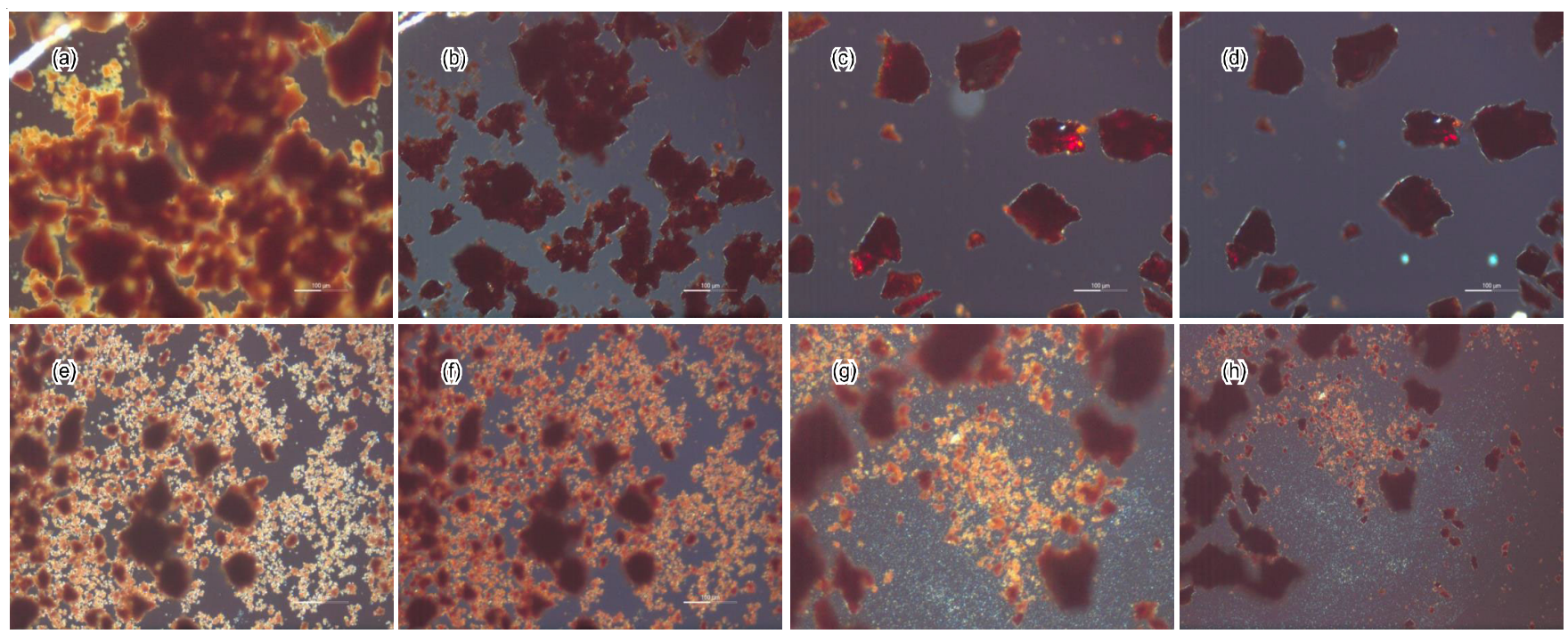

Fig. 5. OPM micrographs of (a) PAPM at $55^{\circ} \mathrm{C}$ (b) PAPM at $260{ }^{\circ} \mathrm{C}$ (c) PAPB at $205{ }^{\circ} \mathrm{C}$ (d) PAPB at $283{ }^{\circ} \mathrm{C}$ (e) PAHM at $250{ }^{\circ} \mathrm{C}$ (f) PAHM at $400{ }^{\circ} \mathrm{C}(\mathrm{g}) \mathrm{PAHB}$ at $253{ }^{\circ} \mathrm{C}(\mathrm{h}) \mathrm{PAHB}$ at $395^{\circ} \mathrm{C}$

lamp at regular time intervals. The decrease in absorbance showed at different intervals of time of irradiation established that there is steady rate of photocrosslinking. The photocrosslinking ability of the polymer was followed by the rate of disappearance of $\mathrm{C}=\mathrm{C}$ bond of photosensitive group in the UV spectrum (Fig. 6). When the polymers were irradiated with UV light, they undergo $2 \pi+2 \pi$ cycloaddition and form photodimers. The absorption intensity decreases rapidly with increasing irradiation time. The decrease in the UV absorption intensity due to photocrosslinking of polymer through $2 \pi+2 \pi$ cyclodimerization of carbon-carbon double bond in the arylidene moiety leads to formation of cyclobutane ring.

$X$-ray diffraction analysis: The powdered wide angle XRD patterns for four synthesized poly(ester amides) were studied at room temperature to examine the crystal behaviour of the polymers. A representative X-ray diffractogram of the polymer PAPM is shown in Fig. 7. The XRD spectrum showed diffraction peaks in the region $2 \theta=16-85^{\circ}$ indicate that these polymers are semi-crystalline in nature. This is due to the presence of methoxy substituent in arylidene diols caused some

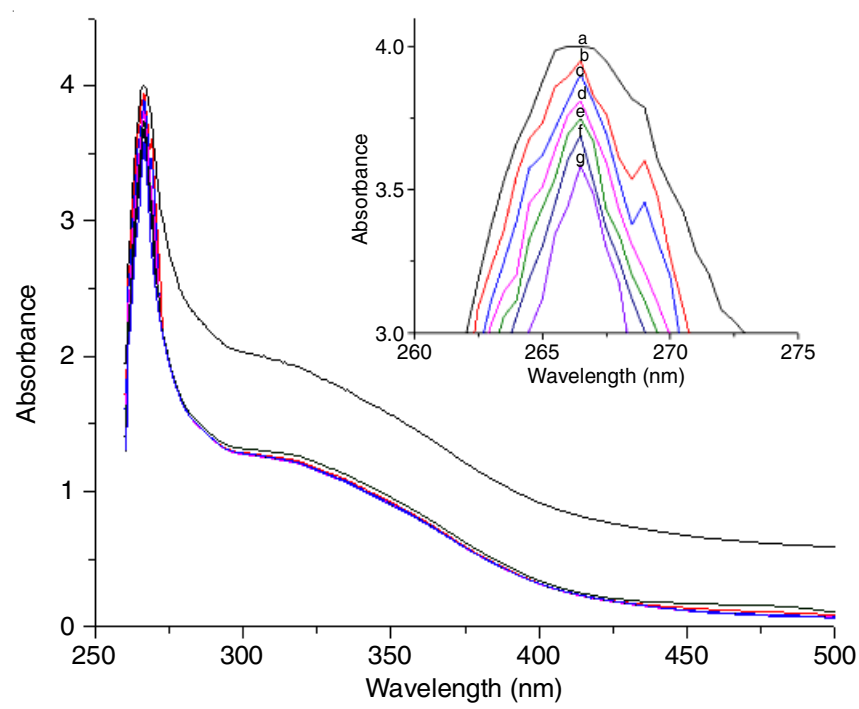

Fig. 6. UV spectrum of PAHB on irradiation of UV light at different time intervals: (a) $0 \mathrm{~min}$, (b) $5 \mathrm{~min}$, (c) $10 \mathrm{~min}$, (d) $20 \mathrm{~min}$, (e) $25 \mathrm{~min}$, (f) $30 \mathrm{~min}$ and (g) $35 \mathrm{~min}$ 


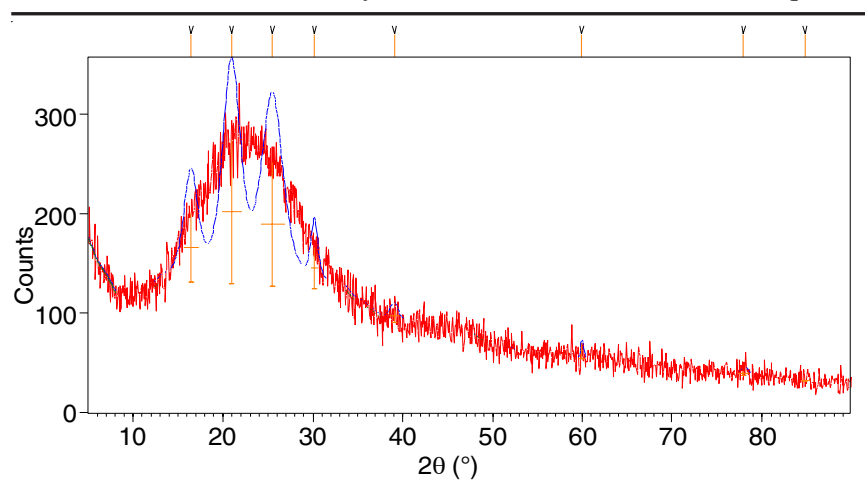

Fig. 7. XRD pattern of PAPM

hindrance between repeating units leading to unsymmetrical orientation and reduced the crystallinity. However, the presence of carbonyl group and carbon-carbon double bonds induces some degree of crystallinity.

Molecular weight determination by gel-permeation chromatography: The molecular weight and molecular weight distribution of polymer PAPM were monitored by gel permeation chromatography technique. Because of the solubility of poly(ester amide) viz. PAPM in THF, it was possible to measure their molecular weights using THF as carrier solvent at room temperature by GPC. The GPC plot of PAPM is shown in Fig. 8. The number average molecular weight $\left(\mathrm{M}_{\mathrm{n}}\right)$, weight average molecular weight $\left(\mathrm{M}_{\mathrm{w}}\right)$, and the polydispersity indices of this poly(ester amide) are listed in Table-4.

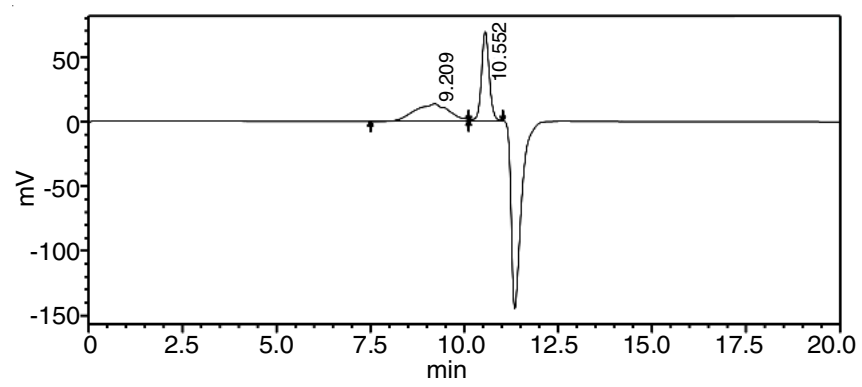

Fig. 8. GPC plot of PAPM

TABLE-4
\begin{tabular}{cccc} 
NUMBER AVERAGE MOLECULAR WEIGHT $\left(\mathrm{M}_{\mathrm{n}}\right)$, \\
WEIGHT AVERAGE MOLECULAR WEIGHT $\left(\mathrm{M}_{\mathrm{w}}\right)$ AND \\
POLYDISPERSITY INDICES OF PAPM \\
\hline Polymer code & $\mathrm{M}_{\mathrm{n}}(\mathrm{g} / \mathrm{mol})$ & $\mathrm{M}_{\mathrm{w}}(\mathrm{g} / \mathrm{mol})$ & PDI \\
\hline PAPM & 48,824 & 70,795 & 1.45 \\
\hline
\end{tabular}

\section{Conclusion}

A series of four new photoactive liquid crystalline poly(ester amides) were synthesized and characterized. The spectral data supported the microstructure of polymer backbone. The resulting polymers showed good solubility in polar, aprotic solvents and the inherent viscosity data revealed that these polymers are of high molecular weight. The TG-DTG thermograms indicated that all the poly(ester amides) are thermally stable. The display of nematic mesophase exhibited by these polymers was confirmed by hot stage optical polarizing microscopy (HOPM) observations. Arylidene cycloalkanones are photoactive chromophores as evidenced by experiments on photocrosslinking by UV irradiation. X-ray diffraction analysis of poly(ester amides) showed that they are semi-crystalline in nature. Considering the results of this work, these poly(ester amides) could be expected to be potential candidates for photoresists and in optical information technology.

\section{CONFLICT OF INTEREST}

The authors declare that there is no conflict of interests regarding the publication of this article.

\section{REFERENCES}

1. U. Edlund and A.-C. Albertsson, Adv. Drug Deliv. Rev., 55, 585 (2003); https://doi.org/10.1016/S0169-409X(03)00036-X.

2. P.A.M. Lips, R. Broos, M.J.M. van Heeringen, P.J. Dijkstra and J. Feijen, Polymer, 46, 7823 (2005): https://doi.org/10.1016/j.polymer.2005.07.013.

3. A. Rodriguez-Galan, L. Franco and J. Puiggali, Polymers, 3, 65 (2010); https://doi.org/10.3390/polym3010065.

4. M. Deng, J. Wu, C.A. Reinhart-King and C.-C. Chu, Biomacromolecules, 10, 3037 (2009);

https://doi.org/10.1021/bm9006437.

5. T.H. Barrows, Synthetic Absorbable Surgical Devices of Poly(esteramides), US Patent 4343931 (1982).

6. J.D. Sudha, J. Polym. Sci. A Polym. Chem., 38, 2469 (2000); https://doi.org/10.1002/1099-0518(20000701)38:13<2469::AIDPOLA190>3.0.CO;2-J.

7. A. Abdolmaleki, S. Mallakpour, R.N. Esmaeli and S. Borandeh, Polym. Plast. Technol. Eng., 55, 911 (2016); https://doi.org/10.1080/03602559.2015.1132431

8. L. Song, B. Du, L. Chen, M. Deng, H. Sun, X. Pang, P. Zhang and X. Chen, J. Polym. Sci. A Polym. Chem., 51, 4722 (2013); https://doi.org/10.1002/pola.26900.

9. I.M. Pinilla, M.B. Martinez, F.Z. Mata and J.A. Galbis, J. Polym. Sci. A Polym. Chem., 36, 67 (1998); https://doi.org/10.1002/(SICI)1099-0518(19980115)36:1<67::AIDPOLA10>3.0.CO;2-B.

10. M.X. Li, R.X. Zhuo and F.Q. Qu, J. Polym. Sci. A Polym. Chem., 40, 4550 (2002);

https://doi.org/10.1002/pola.10547.

11. P. Garg, H. Keul, D. Klee and M. Moller, Macromol. Chem. Phys., 210, 1754 (2009); https://doi.org/10.1002/macp.200900232.

12. Gangadhara and K. Kishore, Polymer, 36, 1903 (1995); https://doi.org/10.1016/0032-3861(95)90938-X.

13. V. Shibaev, Mol. Cryst. Liq. Cryst., 243, 201 (1994); https://doi.org/10.1080/10587259408037770.

14. M. Murali and A.B. Samui, J. Mater. Chem., 20, 2714 (2010); https://doi.org/10.1039/b915137k.

15. S.S. Ankushrao, V.N. Kadam, Y.S. Patil, V.P. Ubale, N.N. Maldar and A.A. Ghanwat, J. Macromol. Sci. Pure Appl. Chem., 54, 124 (2017); https://doi.org/10.1080/10601325.2016.1261625.

16. S.L. Oswal and A.K. Pandya, Iran. Polym. J., 13, 205 (2004).

17. M. Mayavathi, V. Chitra, P. Sathish and D. Roopsingh, Int. J. Chemtech Res., 7, 2956 (2015). 